\title{
Measuring physical activity-related environmental factors: reliability and predictive validity of the European environmental questionnaire ALPHA
}

\author{
Heleen Spittaels' 1 Maïté Verloigne1, Christopher Gidlow², Julien Gloanec³,4, Sylvia Titze5, Charlie Foster6, Jean- \\ Michel Oppert ${ }^{3,4}$, Harry Rutter ${ }^{7}$, Pekka Oja ${ }^{8}$, Michael Sjöström ${ }^{9}$ and Ilse De Bourdeaudhuij ${ }^{* 1}$
}

\begin{abstract}
Background: A questionnaire to assess physical activity related environmental factors in the European population (a 49-item and an 11-item version) was created as part of the framework of the EU-funded project "Instruments for Assessing Levels of PHysical Activity and fitness (ALPHA)". This paper reports on the development and assessment of the questionnaire's test-retest stability, predictive validity, and applicability to European adults.

Methods: The first pilot test was conducted in Belgium, France and the UK. In total 190 adults completed both forms of the ALPHA questionnaire twice with a one-week interval. Physical activity was concurrently measured (i) by administration of the long version of the International Physical Activity Questionnaire (IPAQ) by interview and (ii) by accelerometry (Actigraph ${ }^{\mathrm{TM}}$ device). After adaptations, the second field test took place in Belgium, the UK and Austria; 166 adults completed the adapted questionnaire at two time points, with minimum one-week interval. In both field studies intraclass correlation coefficients (ICC) and proportion of agreement were computed to assess the stability of the two test scores. Predictive validity was examined in the first field test by correlating the results of the questionnaires with physical activity data from accelerometry and long IPAQ-last 7 days.

Results: The reliability scores of the ALPHA questionnaire were moderate-to good in the first field testing (ICC range $0.66-0.86$ ) and good in the second field testing (ICC range $0.71-0.87$ ). The proportion of agreement for the ALPHA short increased significantly from the first (range 50 - 83\%) to the second field testing (range 85 - 95\%). Environmental scales from both versions of the ALPHA questionnaire were significantly associated with self-reported minutes of transport-related walking, and objectively measured low intensity physical activity levels, particularly in women. Both versions were easily administered with an average completion time of six minutes for the 49-item version and less than two minutes for the short version.

Conclusion: The ALPHA questionnaire is an instrument to measure environmental perceptions in relation to physical activity. It appears to have good reliability and predictive validity. The questionnaire is now available to other researchers to investigate its usefulness and applicability across Europe.
\end{abstract}

\section{Background}

Until recently, physical activity promotion research has focused on individual factors (demographics and psychosocial determinants). There is now growing agreement among researchers that the physical or built environment may play an important role as well $[1,2]$. Research into the

* Correspondence: ilse.debourdeaudhuij@ugent.be

1 Department of Movement and Sports Sciences, Ghent University, Watersportlaan 2, 9000 Ghent, Belgium

Full list of author information is available at the end of the article link between the built environment and physical activity is still in its infancy, but is expanding rapidly as demonstrated by the Active Living Research Reference list that comprised 465 references, published in 2008 in various journals $[3,4]$.

However, until now, evidence of the predictive relationship between environmental determinants and physical activity is not very consistent. Wendel-Vos and colleagues found in their review of 47 papers [5] only a few consistent correlates among adults, e.g. between availability of 
physical activity equipment and vigorous physical activity and between trailconnectivity and active commuting. Also in youth, only some specific consistent associations were found between environmental factors and physical activity [6].

One of the challenges of this new research domain is how to measure attributes of the built environment associated with physical activity in a valid, reliable and feasible way. Studies of the physical environment and physical activity have typically used two types of exposure measures: (i) measures of perceptions of the environment using questionnaires; (ii) objective measures of the environment derived from observations of the environment (audits, ground truthing) or through spatial Geographic Information Systems (GIS) data [7].

Early measures of perceptions of the environment were criticised for their lack of metric data (e.g. repeatability, face validity) [8]. The development of perceived environmental measures has emerged outside Europe: in Australia the Social Environmental Individual Determinants (SEID) study conducted by Giles-Corti and colleagues [9] and from three US research centres in North Carolina [10], South Carolina [11], and California [12]. Characteristics of the built environment in Europe differ considerably from those in the US or Australia, especially in terms of housing density and land use mix. This raises questions about the applicability of these questionnaires in a European context. As a consequence a small number of European studies have developed their own or have adapted international questionnaires to the European context. However, a consensus about which environmental questionnaire should be used in Europe has yet to be reached.

One objective of the EU-funded Instruments for Assessing Levels of Physical Activity and Fitness (ALPHA) project, is to propose standardised instruments for physical activity and fitness monitoring across Europe [13]. On the basis of a literature review on currently used environmental questionnaires in Europe and a consensus meeting with an international expert group, a European environmental questionnaire was conceived [14]. Two versions were developed: a form containing 49 items suitable for use in research studies and a shorter 11-item form more suitable for surveillance and monitoring purposes. The development of the questionnaire is described in more detail elsewhere [14]. The next step in the project was to test the reliability and validity of the questionnaire in different languages and in different European countries. The paper reports on assessment of the test-retest stability, predictive validity and feasibility of the ALPHA environmental questionnaire in three European countries.

\section{Methods}

The reliability and validity testing were undertaken in four phases, translation, cognitive testing, and two iterations of field testing. First of all the original version of the ALPHA questionnaire was translated into Dutch, French, and German, followed by cognitive testing. Next a first field test was conducted in three countries. An expert meeting was organised to discuss the results before a second smaller field test was conducted to assess the modified questionnaire.

\section{Translation and cognitive testing}

The English questionnaire (the source) was translated into Dutch, French and German using a standard protocol based on the guidelines of Eurostat [15]. To guide the translation process, conceptual cards were included after each question in the English version. These conceptual cards contained brief notes to explain the format of the questions and the underlying concept to be measured. Two translators, both of whom were native speakers and familiar with the topic, worked independently. They read and translated these conceptual cards into the target language before translation of the questions. After translation the two translators, together with a reviewer, discussed any particular translation problems until a final consensus was reached.

After the translation process, cognitive testing was conducted using cognitive interviewing [16] with at least five persons for each language. Respondents were asked to think aloud while processing each question and deciding how to answer to the question. If something was not clear the interviewer would ask questions to start a discussion.

Through the cognitive testing process, questions that were not clear or comprehensive were identified, discussed with the research team and rephrased.

\section{Field testing I \\ Participants and procedures}

Participants were recruited in three countries (Belgium, UK and France) between October 2008 and January 2009. To ensure some variance in the measured characteristics (e.g. population density), the participants within each country were derived from distinct areas (and thus different built environments). In Belgium a random sample in three different neighbourhoods (town, outskirts of town and village/countryside) was drawn. In each neighbourhood, letters with information about the study were distributed by post. One week after mailing the information letter, potential participants were visited at home and asked if they would participate. In the UK, participants randomly selected from 10 areas of an English city for a previous study [17], were contacted by telephone and appointments arranged to visit willing individuals. In 
France a convenience sample of adults living in the city centre and suburbs of Paris was recruited. Inclusion criteria were: aged 20-65 years, literate in the language of the questionnaire (Dutch, English or French respectively), lived at their current address for at least two months, and without physical disability that would prevent or hamper walking or cycling. The final sample consisted of 190 participants, 60 from Belgium, 64 from UK and 66 from France.

To assess test-retest stability, participants completed, in the presence of a researcher, both forms of the ALPHA questionnaire twice, with an interval of one to two weeks. This is a standard time frame in test-retest studies as it is long enough so that respondents are unlikely to remember their answers to the first testing, but short enough to minimise potential changes in physical activity behaviour. To avoid order effects, participants in each study centre were randomly assigned into two groups: Group $1 \mathrm{com}$ pleted the short version of the questionnaire first (at first and second assessment), followed by the 49-item version, and Group 2 completed the 49-item version first (at first and second assessment), followed by the short version.

To assess predictive validity, physical activity behaviour was measured by accelerometry and long International Physical Activity Questionnaire (IPAQ) last 7 days. Participants were asked to wear accelerometers on the hip during all waking hours for 7 consecutive days following the first visit. Accelerometer recordings were collected at the second visit at which time the researcher interviewadministered the Long IPAQ last 7 day. The interview version was preferred to the self-administered version of the IPAQ because of the tendency towards over reporting of physical activity that has been previously reported [18]. The length of time needed to complete each questionnaire at the first visit was recorded. No incentive was provided for participation.

\section{Measures}

The development of the initial ALPHA environmental questionnaire has been described elsewhere [14]. The instrument included questions on: types of residences in your neighbourhood ( 3 items), distance to local facilities (8 items), walking or cycle infrastructure in your neighbourhood (4 items), maintenance of infrastructure in your neighbourhood (3 items), neighbourhood safety (6 items), how pleasant is your neighbourhood (4 items), cycling and walking network (4 items), home environment (6 items), workplace or study environment (11 items). For the short form of the questionnaire the number of items was reduced to eleven, with a minimum of one item included from each theme. In both versions neighbourhood was defined as "...the area ALL around your home that you could walk to in 10-15 minutes approx $1.5 \mathrm{~km}$ " (or "1 mile" for UK-context).
Self-reported physical activity level was assessed by the Long IPAQ last 7 day http://www.ipaq.ki.se/ipaq.htm. This instrument asks about physical activity behaviour over the last 7 days, according to categories of physical activity intensity, in different contexts such as physical activity as transport, physical activity at work or study, physical activity at home and physical activity in leisure time; it has been shown to be reliable and valid [19].

The MTI Actigraph accelerometer model 7164 was used in Belgium and France, and the Actigraph GT1M was used in the UK. In all cases an epoch time of one minute was used to provide an objective measure of habitual physical activity (over 7 days).

Finally, participants were asked to provide information on their age, height, weight, sex, ethnicity, living situation, educational attainment, occupational status and living environment.

\section{Data reduction}

Adverse items of the environmental questionnaire were recoded and sum scores for each scale were calculated.

For the long IPAQ last 7 day, each activity was expressed in minutes/week by multiplying frequency (day/week) and duration (minutes/day) of the activity. Indices of each domain were calculated by summing all physical activities undertaken for each specific context (work, domestic, transport and leisure). A 'total moderate-intensity and vigorous-intensity physical activity' index was computed by summing all reported physical activities undertaken at moderate and vigorous intensity across the four domains.

Accelerometer data were downloaded by placing the accelerometer into a reader interface unit (RIU) and using specific software (RIU256.exe) [20]. Further the data were analysed by a custom-written program (MAHUFFE.exe, available from http://www.mrc-epid.cam.ac.uk). Accelerometer data were included in the analysis if the minimal number of wearing days was 4 (with at least one weekend day), with a minimum of 10 hours recording time for week days and 8 hours for weekend days, and excluding the relevant hours if there was an interruption in wearing time during the day of more than 60 minutes. To calculate physical activity at low intensity (LPA), at moderate (MPA) and at vigorous physical activity (VPA) Freedson's cut-offs [21] were used $(<1952$ counts per minute for LPA, between $1952-5724$ counts per minute for MPA and $>5724$ counts per minute for VPA).

\section{Statistical analysis}

Cronbach alphas were calculated to assess the internal consistency of each scale of the environmental questionnaire; results $>0.70$ were considered good [22]. Intraclass coefficients (sum scores or items on 5 point scales) were used to compute the coefficient of stability of the scores on the two tests. ICC estimates $>0.75$ were considered as good reliability scores, between $0.50-0.75$ as moderate 
reliability and $<0.50$ as poor reliability [23]. Proportion of agreement was also calculated to measure the proportion of occasions that individuals gave the same score. Proportion of agreement above 0.70 was considered high [24].

Pearson correlations between environmental variables (sum scores) and accelerometer data, and between environmental variables and IPAQ measurements, were calculated to assess predictive validity.

All analyses were performed using SPSS 15.0 software (SPSS Inc., Chicago, IL, USA).

\section{International expert meeting}

After the first field testing an international expert meeting in February 2009 was organised to discuss the results (a list of all experts can be found in additional file 1). Items with lower scores on reliability or validity were discussed and rephrased until consensus was reached.

\section{Field testing II \\ Participants and procedures}

For the second and smaller field testing a new sample was recruited in three countries (Belgium, UK and Austria) between April and May 2009 using the same inclusion criteria as in the first field testing. In Belgium a random sample in three different neighbourhoods (town, outskirts of town, and village/countryside - all different from those in the first field testing) was recruited using the same approach as used in the first field testing. In the UK and Austria, convenience samples comprised university colleagues, students and other associates participated. The final sample consisted of 166 participants, 60 from Belgium, 57 from the UK and 49 from Austria.

In this second round of testing only test-retest stability was assessed for both versions, in a similar way to the first field testing.

\section{Measures}

An adapted version of the ALPHA environmental questionnaire was used. This instrument can be found in additional file 2 (49-item version) and additional file 3 (short version) and on the International Physical activity and Environmental Network (IPEN) website http:// www.ipenproject.org. The same themes as in the original version [14] were used, but some items were changed. For example the answer categories of the short version changed from a four point scale (strongly disagree to strongly agree) to a two point scale (yes-no). The neighbourhood definition was also rephrased, reducing the area around the home to "approximately one kilometer or half a mile" instead of 1.5 kilometer and 1 mile. All changes are detailed in additional file 4 . No other measures were included in the second field testing.

\section{Data reduction and statistical analysis}

Adverse items of the environmental questionnaire were recoded and sum scores for each scale were made. Cronbach alphas were calculated to assess the internal consis- tency of each scale of the environmental questionnaire. Intraclass correlation coefficients (sum scores or items on 5 point scales) and proportion of agreement (separate items) were used to compute the coefficient of stability of the scores on the two tests.

\section{Results \\ Field testing I}

Most participants in the first field testing were female (63\%); most participants lived in an urban area (86.3\%) and were employed (78.9\%). Average age was 40 years and average BMI $25 \mathrm{~kg} / \mathrm{m}^{2}$ (see Table 1). Cronbach alphas ranged from 0.57-0.76 (data not shown) except for the walking and cycling infrastructure scale (alpha $=0.37$ ).

\section{Feasibility}

Mean $( \pm$ SD) time for questionnaire completion during the first assessment was 6 minutes 47 seconds $( \pm 2 \mathrm{~min}$ ) for the 49-item version and 1 minute and 46 seconds $( \pm 39$ seconds) for the short version.

\section{Test-retest reliability}

Table 2 shows answer frequencies and mean score of each item on the first assessment of the ALPHA environmental questionnaire and its test-retest reliability scores. The ICCs of the sum scores of each of the nine subscales ranged from 0.66 to 0.86 . Six of the nine sum scores were above 0.75 which indicates good reliability; three of them (residential density, infrastructure and maintenance) were between $0.60-0.75$, which shows moderate reliability. ICC of the individual items ranged from 0.44-0.82 with the lowest scores for particular safety items and items of the cycling and walking network scale. Proportion of agreement for all individual items ranged from 5299\%.

Table 3 summarises the answer frequencies and mean scores for each item on the first assessment of the ALPHA short, together with test-retest reliability scores (ICC and proportion of agreement). The ICC of the total sum score was 0.75 which indicates good test-retest stability. The ICC for individual items ranged from $0.50-0.80$ and thus showed only moderate reliability. Proportion of agreement was also low ranging from $50-83 \%$, with only two items equal or above $70 \%$.

\section{Predictive validity}

Tables 4 and 5 show the significant correlations of the subscale of the ALPHA questionnaires (both forms) with the physical activity measurements (both IPAQ and accelerometers).

All significant correlations were in the hypothesised directions (higher environmental support of physically activity was correlated with higher levels of physically activity) except for the negative correlations found between the scales 'availability of sidewalks' and 'safety from traffic' with some IPAQ variables. The size of all correlations ranged from $0.19-0.38$ which is an indication 
Table 1: Characteristics of the participants in the first and second field testing

\begin{tabular}{|c|c|c|c|c|}
\hline \multirow[b]{2}{*}{ Age (years) } & \multicolumn{2}{|c|}{ First field testing $\mathrm{N}=190$} & \multicolumn{2}{|c|}{ Second field testing $\mathrm{N}=166$} \\
\hline & \multicolumn{2}{|c|}{$40.52 \pm 12.46$} & \multicolumn{2}{|c|}{$32.89 \pm 12.89$} \\
\hline \multirow[t]{2}{*}{ BMI $\left(\mathbf{k g} / \mathbf{m}^{2}\right)$} & \multicolumn{2}{|c|}{$25.19 \pm 4.37$} & \multicolumn{2}{|c|}{$23.94 \pm 3.56$} \\
\hline & $\mathbf{N}$ & $\%$ & $\mathbf{N}$ & $\%$ \\
\hline \multicolumn{5}{|l|}{ Sex } \\
\hline Male & 71 & 37.4 & 88 & 53 \\
\hline Female & 119 & 62.6 & 78 & 47 \\
\hline \multicolumn{5}{|l|}{ Nationality } \\
\hline Belgian & 60 & 31.6 & 58 & 35.2 \\
\hline British & 66 & 34.7 & 56 & 33.9 \\
\hline French & 64 & 33.7 & - & - \\
\hline Austrian & - & - & 49 & 29.7 \\
\hline \multicolumn{5}{|l|}{ Living situation } \\
\hline with partner and children & 69 & 36.3 & 53 & 31.9 \\
\hline with partner & 46 & 24.2 & 37 & 22.3 \\
\hline with children & 20 & 10.5 & 2 & 1.2 \\
\hline with parents & 30 & 15.8 & 34 & 20.5 \\
\hline Alone & 25 & 13.2 & 26 & 15.7 \\
\hline with friends/other & & - & 14 & 8.4 \\
\hline \multicolumn{5}{|l|}{ Higher education } \\
\hline Yes & 95 & 50 & 135 & 81.3 \\
\hline No & 95 & 50 & 31 & 18.7 \\
\hline \multicolumn{5}{|l|}{ Having a job } \\
\hline Yes & 150 & 78.9 & 98 & 59.4 \\
\hline No & 40 & 21.1 & 67 & 40.6 \\
\hline \multicolumn{5}{|l|}{ NS-SEC } \\
\hline Managerial and professional occupations & 40 & 24.5 & 23 & 23.5 \\
\hline Intermediate occupations & 84 & 51.5 & 65 & 66.3 \\
\hline Routine and manual occupations & 39 & 23.9 & 10 & 10.2 \\
\hline \multicolumn{5}{|l|}{ Place of residence } \\
\hline Town & 103 & 54.2 & 77 & 46.4 \\
\hline Outskirts of the town & 61 & 32.1 & 51 & 30.7 \\
\hline Village/Countryside & 26 & 13.7 & 38 & 22.9 \\
\hline
\end{tabular}

NS-SEC: National Statistics Socio-economic Classification

of moderate validity. Environmental scales of ALPHA were mostly significantly correlated with minutes of transport-related walking as measured with the IPAQ, both in men and women. Very few significant correlations were found with accelerometers in men, however there were several significant correlations found in women, especially with physical activity at low intensity.
The sum score calculated from the ALPHA short was significantly correlated with both IPAQ and accelerometers in men and women. All significant correlations were in the expected directions and ranged from 0.21-0.34.

\section{International expert meeting}

Based on the results of the first field testing wording and answer categories of specific items with lower reliability 
Table 2: First field testing of the ALPHA questionnaire ( $N=190)$ : Answer frequencies, mean scores, and test-retest reliability scores.

Answer Frequencies and mean score of each item on the first assessment

Test-retest reliability

scores

\section{Types of residences}

\begin{tabular}{|c|c|c|c|c|c|c|c|c|}
\hline Item/scale & None & A Few & Some & Most & All & Mean (SD) & Agreement, \% & ICC \\
\hline 1. Residential density & & & & & & & & $0.68^{\mathrm{a}}$ \\
\hline a) Detached houses & 19.5 & 31.1 & 22.6 & 18.4 & 8.4 & $2.7(1.2)$ & 70 & 0.80 \\
\hline b) Semi-detached townhouses, terraced houses & 8.5 & 29.6 & 19.6 & 37.6 & 4.8 & $3.0(1.1)$ & 66 & 0.71 \\
\hline c) Flats of 6 floors or more & 43.0 & 24.7 & 15.1 & 12.9 & 4.3 & $2.1(1.2)$ & 66 & 0.72 \\
\hline
\end{tabular}

Travel time to facilities

\begin{tabular}{|c|c|c|c|c|c|c|c|c|}
\hline & $1-5 \min$ & 6-10 min & $11-20 \mathrm{~min}$ & $21-30 \mathrm{~min}$ & $>30 \mathrm{~min}$ & Mean (SD) & Agreement, \% & ICC \\
\hline 2. Distance to local facilities & & & & & & & & $0.86^{b}$ \\
\hline a) Local shop & 64.7 & 25.8 & 7.9 & 0.5 & 1.1 & $1.5(0.8)$ & 76 & 0.74 \\
\hline b) Supermarket & 20.5 & 24.7 & 26.3 & 9.5 & 8.9 & $2.5(1.2)$ & 67 & 0.78 \\
\hline c) Local services & 20.6 & 31.2 & 30.2 & 11.1 & 6.9 & $2.5(1.1)$ & 66 & 0.80 \\
\hline d) Restaurant & 46.8 & 27.9 & 16.8 & 3.2 & 5.3 & $1.9(1.1)$ & 62 & 0.71 \\
\hline e) Fast-food restaurant & 27.4 & 25.3 & 16.3 & 14.2 & 16.8 & $2.7(1.4)$ & 65 & 0.82 \\
\hline f) Busstop & 74.2 & 17.4 & 6.8 & 0.5 & 1.1 & $1.4(0.7)$ & 81 & 0.75 \\
\hline g) Sport and leisure facility & 16.3 & 25.3 & 28.9 & 14.2 & 15.3 & $2.9(1.3)$ & 63 & 0.70 \\
\hline h) Open recreation area & 37.4 & 24.2 & 23.2 & 8.4 & 6.8 & $2.2(1.2)$ & 59 & 0.73 \\
\hline
\end{tabular}

Acceptance of statements

Strongly disagree $\quad$ Somewhat disagree $\quad$ Somewhat agree $\quad$ Strongly agree I don't know $\quad$ Mean (SD) Agreement, \% ICC

3. Total Infrastructure $0.68 \mathrm{~b}$

Cycling Infrastructure, $\quad 0.67 \mathrm{c}$

Walking infrastructure $\quad 0.66 \mathrm{~d}$ 
Table 2: First field testing of the ALPHA questionnaire ( $N=190)$ : Answer frequencies, mean scores, and test-retest reliability scores. (Continued)

\begin{tabular}{|c|c|c|c|c|c|c|c|c|}
\hline a) special lanes, routes or paths to cycle & 18.4 & 13.7 & 37.9 & 28.9 & 1.1 & $2.8(1.1)^{\#}$ & 64 & 0.75 \\
\hline b) traffic-free cycle routes & 41.6 & 24.2 & 19.5 & 12.6 & 2.1 & $2.0(1.1)^{\#}$ & 59 & 0.60 \\
\hline c) sidewalks & 2.6 & 5.8 & 18.4 & 72.6 & 0.5 & $3.6(0.7) \#$ & 71 & 0.60 \\
\hline d) pedestrian zones for shopping & 55.3 & 11.6 & 16.8 & 14.7 & 1.6 & $1.9(1.2) \#$ & 64 & 0.69 \\
\hline 4. Maintenance & & & & & & & & $0.66^{b}$ \\
\hline a) cycling paths are well maintained & 9.5 & 10.1 & 39.7 & 20.6 & 20.7 & $2.9(0.9) \#$ & 60 & 0.61 \\
\hline b) sidewalks are well maintained & 5.3 & 18.5 & 56.1 & 19.0 & 1.1 & $2.9(0.8) \#$ & 65 & 0.58 \\
\hline \multirow[t]{2}{*}{ c) public recreation facilities are well maintained } & 5.3 & 9.5 & 47.1 & 32.8 & 5.3 & $3.1(0.8)^{\#}$ & 62 & 0.61 \\
\hline & Strongly disagree & Somewhat disagree & Somewhat agree & Strongly agree & & Mean (SD) & Agreement, \% & ICC \\
\hline 5. Safety & & & & & & & & $0.75^{b}$ \\
\hline Safety from crime & & & & & & & & $0.77^{e}$ \\
\hline Safety from traffic & & & & & & & & $0.69^{f}$ \\
\hline a) not safe to leave a bicycle locked & 16.5 & 28.7 & 33.5 & 21.3 & & $2.6(1.0)$ & 53 & 0.53 \\
\hline b) not enough safe places to cross busy streets & 18.0 & 46.0 & 31.2 & 4.8 & & $2.2(0.8)$ & 52 & 0.44 \\
\hline c) Walking is unsafe because of the traffic & 35.4 & 50.3 & 12.7 & 1.6 & & $1.8(0.9)$ & 64 & 0.54 \\
\hline d) Cycling is unsafe because of the traffic & 20.6 & 44.4 & 27.5 & 7.4 & & $2.2(0.9)$ & 61 & 0.64 \\
\hline $\begin{array}{l}\text { e) unsafe during the day because of the level of } \\
\text { crime }\end{array}$ & 58.2 & 31.7 & 9.0 & 1.1 & & $1.5(0.7)$ & 71 & 0.61 \\
\hline $\begin{array}{l}\text { f) unsafe during the night because of the level of } \\
\text { crime }\end{array}$ & 37.0 & 32.8 & 22.2 & 7.9 & & $2.0(1.0)$ & 68 & 0.81 \\
\hline 6. Pleasant & & & & & & & & $0.81^{b}$ \\
\hline Aesthetics & & & & & & & & $0.79 \mathrm{~g}$ \\
\hline a) a pleasant environment for walking and cycling & 2.1 & 21.6 & 52.6 & 23.7 & & $2.9(0.7)$ & 69 & 0.70 \\
\hline b) generally free from litter or graffiti & 10.5 & 29.5 & 43.7 & 16.3 & & $2.7(0.9)$ & 66 & 0.61 \\
\hline c) trees along the streets & 12.6 & 16.8 & 33.7 & 36.8 & & $2.9(1.0)$ & 62 & 0.73 \\
\hline $\begin{array}{l}\text { d) a lot of badly maintained, unoccupied or ugly } \\
\text { buildings }\end{array}$ & 38.4 & 35.8 & 20.5 & 5.3 & & $1.9(0.9)$ & 66 & 0.65 \\
\hline 7. Cycling \& walking network & & & & & & & & $0.80^{\mathrm{b}}$ \\
\hline Connectivity & & & & & & & & $0.92^{\mathrm{h}}$ \\
\hline
\end{tabular}


Table 2: First field testing of the ALPHA questionnaire ( $N=190)$ : Answer frequencies, mean scores, and test-retest reliability scores. (Continued)

\begin{tabular}{|c|c|c|c|c|c|c|c|c|}
\hline a) Cycling is quicker than driving during the day & 20.0 & 28.4 & 27.9 & 15.3 & 8.4 & $2.4(1.0)^{\#}$ & 53 & 0.57 \\
\hline $\begin{array}{l}\text { b) Easier to take shortcuts with a bicycle or walking } \\
\text { that with a car }\end{array}$ & 10.5 & 16.3 & 41.6 & 27.9 & 3.7 & $2.9(0.9)^{\#}$ & 57 & 0.52 \\
\hline c) many intersections & 5.3 & 21.6 & 43.7 & 26.3 & 3.2 & $2.9(0.8) \#$ & 60 & 0.61 \\
\hline \multirow{3}{*}{$\begin{array}{l}\text { d) many different routes for cycling or walking } \\
\text { from place to place }\end{array}$} & 2.1 & 23.2 & 48.9 & 22.6 & 3.2 & $3.0(0.7)^{\#}$ & 66 & 0.65 \\
\hline & \multicolumn{3}{|c|}{ Availability of } & & & & Agreement, \% & ICC \\
\hline & yes & no & & & & & & \\
\hline 8. Home environment & & & & & & & & $0.86^{b}$ \\
\hline a) Bicycle & 61.1 & 38.9 & & & & & 99 & \\
\hline b) Garden & 72.0 & 28.0 & & & & & 96 & \\
\hline c) Small sports equipment & 70.0 & 30.0 & & & & & 94 & \\
\hline d) Eercise equipment & 47.9 & 52.1 & & & & & 93 & \\
\hline e) Car & 82.1 & 17.9 & & & & & 98 & \\
\hline f) Dog & 24.7 & 75.3 & & & & & 99 & \\
\hline 9. Workplace or study environment & & & & & & & & $0.82^{b}$ \\
\hline a) Escalators & 61.0 & 39.0 & & & & & 91 & \\
\hline b) Stairs & 89.9 & 10.1 & & & & & 94 & \\
\hline c) Fitness centre/equipment & 27.7 & 72.3 & & & & & 93 & \\
\hline d) Bicycles provided by employer or school & 13.8 & 86.2 & & & & & 93 & \\
\hline e) A safe place to leave a bike & 66.5 & 33.5 & & & & & 85 & \\
\hline f) A free car park & 65.4 & 34.6 & & & & & 90 & \\
\hline g) Showers and changing rooms & 57.9 & 42.1 & & & & & 92 & \\
\hline h) Exercise classes & 22.6 & 77.4 & & & & & 92 & \\
\hline i) Sports club & 22.0 & 48.0 & & & & & 92 & \\
\hline j) Employer subsidised public transport/cycling & 44.7 & 55.3 & & & & & 85 & \\
\hline
\end{tabular}

\# without 'I don't know' variable

a weighted by the following formula $=$ item $1 a+\left(12^{*}\right.$ item $\left.1 b\right)+\left(50^{*}\right.$ item $\left.1 c\right)$; $b$ : total sum score of all items; $c$ : sum score of items $3 a \& 3 b$; : sum score of items $3 c \& 3 d$; e: sum score of reversed items $5 a, 5 e \& 5 f ;$ f: sum score of reversed items 5b, 5c, $5 d$; 9 :sum score of items $6 b, 6 c$, reversed $6 d$; h:sum score of items $7 b, 7 c \& 7 d$ 
Table 3: First field testing of the ALPHA short ( $N=190)$ : Answer frequencies, mean scores, and test-retest reliability scores.

Answer Frequencies and mean score of each item on the first assessment

Test-retest reliability scores

Strongly disagree Somewhat disagree Somewhat agree Strongly agree Idon't know Mean (SD)

Agreement, \% ICC

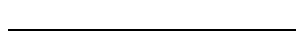

Total

A. Most of the houses in my neighbourhood are detached houses

B. Many shops, stores, markets or other places to buy things I need are within easy walking distance of my home

C. There is a transit stop (such as bus stop, train, trolley or tram station) within easy walking distance of my home

D. There is an open recreation area (e.g. park, beach or other open space) within easy walking distance of my home

E. There are many different routes for cycling or walking from place to place in my

neighbourhood so I don't have to go the same way every time

F. Walking and cycling are unsafe because of the traffic in my neighbourhood

G. Walking and cycling are unsafe because of the level of crime in my neighbourhood

H. My local neighbourhood is a pleasant environment for walking and cycling

I. I have access to exercise and sports equipment at home e.g. weights, racquets, skis for personal use

J. My workplace provides facilities to support me walking or cycling to work e.g. changing rooms, bike storage

K. I have access to exercise and sports facilities at work e.g. fitness centre/equipment, stairs

\#without "not applicable"; a: total sum score of all items 
Table 4: First field testing ( $=190$ ): Pearson correlations between the ALPHA questionnaire and ALPHA short with long last 7 day IPAQ, stratified by sex (only statistically significant values are shown).

\section{ALPHA \& IPAQ} questionnaire)

Density score $(1 \mathrm{a}, 1 \mathrm{~b}, 1 \mathrm{c})$

\section{Male}

Female

$0.20^{*}$

$0.21^{*}$

Distance to local facilities (2a to $2 \mathrm{~h}$ )

$\begin{array}{lll}\text { Male } & - & -0.33^{* *} \\ \text { Female } & 0.25^{*} & -0.20^{*}\end{array}$

$-0.32^{* *}$

$0.32 *$

Availability of sidewalks (3c, 3d)

Male

$0.32 *$

Female

$-0.20^{*}$

$-0.19^{*}$

Maintenance $(4 a, 4 b, 4 c, 4 d) \quad$ Male

Female

Safety from traffic (reversed $5 b, 5 c, 5 d$ ) Male

Female

$-0.31^{* *}$

$-0.30^{* *}$

$-0.22^{*}$

$0.22^{*}$

Aesthetics (6b, 6c, 6d)

$$
\text { Male }
$$

Female

$0.19^{*}-0.25^{* *}$

$-0.23^{*}$

Cycling and walking network (7a, 7d) Male

Female

$0.24^{*}$

Connectivity $(7 b, 7 c, 7 d)$

Male

$0.28^{*}$

Home environment (8a to 8 f)

Female

Male

$0.38^{* *}$

Female 
Table 4: First field testing ( $N=190)$ : Pearson correlations between the ALPHA questionnaire and ALPHA short with long last 7 day IPAQ, stratified by sex (only statistically significant values are shown). (Continued)

Female

\section{ALPHA short \& IPAQ}

Total sum of 11 items

Male

$0.34^{* *}$

$0.25^{*}$

a men: $\mathrm{N}=70$, women: $\mathrm{N}=120$

Total_PA: total minutes PA/week (low, moderate, vigorous in all domains); MVPA:total minutes PA/week at moderate to vigorous intensity; walking for transport: total minutes transport-related

walking/week; Cycling for transport: total minutes transport-related cycling/week; Total transport: total minutes PA/week by active transportation (walking and/or cycling for transport); Total

walking: total minutes walking/week (job, transport, leisure time); Leisure time PA:total minutes PA/week in leisure time; Home PA: total minutes PA/week in and around the house (inclusive gardening); ${ }^{*}<<0.05 ;{ }^{* *} p<0.01$ 
Table 5: First field testing ( $N=190)$ : Pearson correlations between ALPHA and ALPHA short questionnaire with accelerometer, stratified by sex (only statistically significant values are shown).

\begin{tabular}{|c|c|c|c|c|c|}
\hline Name of the scale (number of items in the questionnaire) & Sex & Total PA & VPA & MVPA & LPA \\
\hline \multirow[t]{2}{*}{ Density score (1a, 1b, 1c) } & Male & & & & \\
\hline & Female & & & & \\
\hline \multirow[t]{2}{*}{ Distance to local facilities ( $2 \mathrm{a}, 2 \mathrm{~b}, 2 \mathrm{c}, 2 \mathrm{~d}, 2 \mathrm{e}, 2 \mathrm{f}, 2 \mathrm{~g}, 2 \mathrm{~h})$} & Male & & & & \\
\hline & Female & & & & \\
\hline \multirow[t]{2}{*}{ Availability of sidewalks (3c, 3d) } & Male & & & & \\
\hline & Female & & & & \\
\hline \multirow[t]{2}{*}{ Maintenance (4a, 4b, 4c, 4d) } & Male & & & & \\
\hline & Female & & & & \\
\hline \multirow[t]{2}{*}{ Safety from traffic (reversed $5 b, 5 c, 5 d$ ) } & Male & & & & \\
\hline & Female & & $0.20^{*}$ & & \\
\hline \multirow[t]{2}{*}{ Aesthetics $(6 b, 6 c, 6 d)$} & Male & & & & \\
\hline & Female & $0.25^{*}$ & & & $0.26^{*}$ \\
\hline \multirow[t]{2}{*}{ Cycling and walking network $(7 \mathrm{a}, 7 \mathrm{~d})$} & Male & & & & \\
\hline & Female & $0.28^{* *}$ & & & 0.29 \\
\hline \multirow[t]{2}{*}{ Connectivity (7b, 7c, 7d) } & Male & & & & \\
\hline & Female & & & $0.24^{*}$ & \\
\hline \multirow[t]{2}{*}{ Home environment $(8 \mathrm{a}, 8 \mathrm{~b}, 8 \mathrm{c}, 8 \mathrm{~d}, 8 \mathrm{e}, 8 \mathrm{f})$} & Male & & & & \\
\hline & Female & $0.21^{*}$ & & & $0.21^{*}$ \\
\hline \multirow[t]{2}{*}{ Workplace or study environment (9a, 9b, 9c, 9d, 9e, 9f, 9h, 9i, 9j) } & Male & & & & $0.32^{*}$ \\
\hline & Female & $0.34^{* *}$ & & & $0.32^{* *}$ \\
\hline \multicolumn{6}{|l|}{ ALPHA short \& accelerometer } \\
\hline \multirow[t]{2}{*}{ Total sum of 11 items } & Male & & & & $0.29^{*}$ \\
\hline & Female & $0.26^{* *}$ & & $0.28^{* *}$ & $0.28^{*}$ \\
\hline
\end{tabular}

a men: $\mathrm{N}=65$ : women: $\mathrm{N}=106$

Total_PA: total minutes PA/week (low, moderate, vigorous in all domains); VPA: total minutes PA/week at vigorous intensity ( $>5724$ counts per minute); MVPA:total minutes PA/week at moderate to vigorous intensity ( $>1951$ counts per minute); LPA: total minutes PA/week at low intensity (below 1952 counts per minute); ${ }^{*} p<0.05 ; * * 0<0.01$

scores were modified following discussions at the expert meeting (see Additional file 4).

\section{Field testing II}

In the second field testing almost half (47\%) of the participants were female. Most of the participants lived in an urban area (77.1\%), and were employed (59\%), with an average age of 33 years and an average BMI of $24 \mathrm{~kg} / \mathrm{m} 2$ (see Table 1).

Internal consistency

Cronbach alphas ranged from $0.65-0.82$ except for the pleasant environment scale (alpha $=0.34)$ (data not shown). 
Table 6: Second field testing of the ALPHA questionnaire ( $N=166)$ : Answer frequencies; mean scores and its test-retest reliability scores.

\begin{tabular}{|c|c|c|c|c|c|c|c|c|}
\hline \multirow[b]{2}{*}{ Item/scale } & \multicolumn{6}{|c|}{ Answer Frequencies and mean score of each item on the first assessment } & \multicolumn{2}{|c|}{$\begin{array}{c}\text { Test-retest reliability } \\
\text { scores }\end{array}$} \\
\hline & None & A Few & Some & Most & All & Mean (SD) & Agreement \% & ICC \\
\hline 1. Residential density & & & & & & & & $0.80^{\mathrm{a}}$ \\
\hline a) Detached houses & 18.5 & 27.8 & 27.8 & 22.2 & 3.7 & $2.65(1.1)$ & 77 & 0.81 \\
\hline b) Semi-detached houses or terraced houses & 3.7 & 15.2 & 39.0 & 39.0 & 3.0 & $3.23(0.9)$ & 59 & 0.56 \\
\hline \multirow[t]{3}{*}{ c) Apartment buildings or blocks of flats } & 22.0 & 37.8 & 27.4 & 11.6 & 1.2 & $2.32(1.0)$ & 73 & 0.80 \\
\hline & \multicolumn{8}{|c|}{ Travel time to facilities } \\
\hline & $1-5 \mathrm{~min}$ & $6-10 \mathrm{~min}$ & $11-20 \mathrm{~min}$ & $21-30 \mathrm{~min}$ & $>30 \min$ & Mean (SD) & Agreement \% & ICC \\
\hline 2. Distance to local facilities & & & & & & & & $0.87^{b}$ \\
\hline a) Local shop & 57.2 & 22.9 & 13.9 & 3.0 & 3.0 & $1.7(1.0)$ & 75 & 0.80 \\
\hline b) Supermarket & 43.0 & 24.2 & 20.6 & 5.5 & 6.7 & $2.1(1.2)$ & 75 & 0.82 \\
\hline c) Local services & 30.7 & 29.5 & 21.7 & 12.0 & 6.0 & $2.3(1.2)$ & 67 & 0.77 \\
\hline d) Restaurant, café, pub.. & 50.0 & 30.1 & 12.0 & 4.8 & 3.0 & $1.8(1.0)$ & 75 & 0.72 \\
\hline e) Fast-food restaurant & 36.2 & 23.3 & 13.8 & 12.1 & 14.7 & $2.5(1.5)$ & 60 & 0.87 \\
\hline f) Bus stop & 72.7 & 17.6 & 5.5 & 3.0 & 1.2 & $1.4(0.8)$ & 79 & 0.74 \\
\hline g) Sport and leisure facility & 18.7 & 29.5 & 27.7 & 11.4 & 12.7 & $2.7(1.2)$ & 65 & 0.75 \\
\hline \multirow[t]{3}{*}{ h) Open recreation area } & 48.5 & 27.9 & 10.3 & 6.1 & 7.3 & $3.5(0.8)$ & 76 & 0.76 \\
\hline & \multicolumn{8}{|c|}{ Acceptance of statements } \\
\hline & Strongly disagree & Somewhat disagree & Somewhat agree & Strongly agree & & Mean (SD) & Agreement \% & ICC \\
\hline 3. Infrastructure & & & & & & & & $0.79 \mathrm{~b}$ \\
\hline Pedestrian infrastructure & & & & & & & & $0.75^{c}$ \\
\hline Cycling infrastructure & & & & & & & & $0.74^{d}$ \\
\hline a) Sidewalks & 4.8 & 7.8 & 17.5 & 69.9 & & $3.5(0.8)$ & 73 & 0.74 \\
\hline b) pedestrian zones or pedestrian trails & 24.7 & 23.5 & 28.9 & 22.9 & & $2.5(1.1)$ & 59 & 0.65 \\
\hline
\end{tabular}


Table 6: Second field testing of the ALPHA questionnaire ( $N=166)$ : Answer frequencies; mean scores and its test-retest reliability scores. (Continued)

\begin{tabular}{|c|c|c|c|c|c|c|c|c|}
\hline c) Special lanes, routes or paths for cycling & 18.8 & 17.0 & 33.9 & 30.3 & & $2.8(1.1)$ & 62 & 0.69 \\
\hline d) cycle routes separated from traffic & 26.7 & 24.2 & 28.5 & 20.6 & & $2.4(1.1)$ & 61 & 0.68 \\
\hline & Strongly disagree & Somewhat disagree & Somewhat agree & Strongly agree & Not applicable & Mean (SD) & Agreement \% & ICC \\
\hline 4. Maintenance & & & & & & & & $0.74^{\# b}$ \\
\hline a) sidewalks are well maintained & 7.9 & 13.4 & 42.1 & 35.4 & 1.2 & $3.1(0.9$ & 57 & $0.60^{\#}$ \\
\hline b) cycling paths are well maintained & 15.3 & 13.5 & 40.5 & 23.9 & 6.7 & $2.8(1.0)$ & 63 & $0.55^{\#}$ \\
\hline \multirow[t]{2}{*}{$\begin{array}{l}\text { c) Play areas, playgrounds, parks or other open spaces } \\
\text { are well maintained }\end{array}$} & 3.1 & 11.7 & 47.2 & 35.0 & 3.1 & $3.2(0.8)$ & 66 & $0.62^{\#}$ \\
\hline & Strongly disagree & Somewhat disagree & Somewhat agree & Strongly agree & & Mean (SD) & Agreement \% & ICC \\
\hline 5. Safety & & & & & & & $0.71^{b}$ & \\
\hline Safety from crime & & & & & & & $0.78^{e}$ & \\
\hline Safety from traffic & & & & & & & $0.68^{f}$ & \\
\hline a) dangerous to leave a bicycle locked & 28.5 & 40.0 & 20.6 & 10.9 & & $2.1(1.0)$ & 66 & 0.69 \\
\hline b) not enough safe places to cross busy streets & 41.2 & 37.0 & 18.2 & 3.6 & & $1.8(0.8)$ & 61 & 0.57 \\
\hline c) Walking is dangerous because of the traffic & 47.3 & 40.6 & 10.3 & 1.8 & & $1.7(0.7)$ & 68 & 0.58 \\
\hline d) Cycling is dangerous because of the traffic & 35.8 & 37.0 & 24.2 & 3.0 & & $2.0(0.9)$ & 62 & 0.61 \\
\hline $\begin{array}{l}\text { e) dangerous during the day because of the level of } \\
\text { crime }\end{array}$ & 73.9 & 23.0 & 2.4 & 0.6 & & $1.3(0.5)$ & 74 & 0.57 \\
\hline $\begin{array}{l}\text { f) dangerous during the night because of the level of } \\
\text { crime }\end{array}$ & 43.1 & 44.0 & 8.6 & 4.3 & & $1.7(0.8)$ & 69 & 0.60 \\
\hline 6. Pleasant & & & & & & & & $0.84^{b}$ \\
\hline Aesthetics & & & & & & & & $0.74 \mathrm{~g}$ \\
\hline \multirow[t]{2}{*}{ a) a pleasant environment for walking and cycling } & 3.6 & 19.3 & 45.2 & 31.9 & $3.1(0.8)$ & & 68 & 0.65 \\
\hline & None & A few & Some & Plenty & & Mean (SD) & Agreement \% & ICC \\
\hline b) litter or graffiti & 36.7 & 34.9 & 20.5 & 7.8 & & $2.0(0.9)$ & 71 & 0.82 \\
\hline c) trees along the streets & 15.1 & 18.7 & 37.3 & 28.9 & & $2.8(1.0)$ & 66 & 0.72 \\
\hline d) badly maintained, unoccupied or ugly buildings & 40.6 & 44.2 & 9.7 & 5.5 & & $1.8(0.8)$ & 68 & 0.57 \\
\hline
\end{tabular}


Table 6: Second field testing of the ALPHA questionnaire ( $N=166)$ : Answer frequencies; mean scores and its test-retest reliability scores. (Continued)

\begin{tabular}{|c|c|c|c|c|c|c|c|}
\hline & Strongly disagree & Somewhat disagree & Somewhat agree & Strongly agree & Mean (SD) & Agreement \% & ICC \\
\hline 7. Cycling and walking network & & & & & & & $0.84^{b}$ \\
\hline Connectivity & & & & & & & $0.91^{\mathrm{h}}$ \\
\hline a) Many shortcuts for walking & 6.0 & 27.7 & 47.0 & 19.3 & $2.8(0.8)$ & 67 & 0.58 \\
\hline b) Cycling is quicker than driving during the day & 19.9 & 31.9 & 25.9 & 22.3 & $2.5(1.0)$ & 67 & 0.79 \\
\hline c) many road junctions & 7.2 & 35.5 & 39.8 & 17.5 & $2.7(0.8)$ & 61 & 0.61 \\
\hline $\begin{array}{l}\text { d) many different routes for cycling or walking from } \\
\text { place to place }\end{array}$ & 3.6 & 19.3 & 56.0 & 21.9 & $2.9(0.7)$ & 63 & 0.54 \\
\hline
\end{tabular}

Availability of

\begin{tabular}{|c|c|c|c|c|}
\hline & yes & no & Agreement \% & ICC \\
\hline 8. Home environment & & & & $0.72^{b}$ \\
\hline a) Bicycle & 81.3 & 18.7 & 99 & \\
\hline b) Garden & 76.5 & 23.5 & 95 & \\
\hline c) Small sports equipment & 86.7 & 13.3 & 94 & \\
\hline d) Exercise equipment & 60.2 & 39.2 & 96 & \\
\hline e) Car & 86.1 & 13.3 & 98 & \\
\hline f) Dog & 19.3 & 80.1 & 98 & \\
\hline 9. Workplace or study environment & & & & $0.83 \mathrm{~b}$ \\
\hline a) Escalators & 47.4 & 52.6 & & 91 \\
\hline b) Stairs & 89.5 & 10.5 & & 95 \\
\hline c) Fitness centre/equipment & 34.9 & 65.1 & & 91 \\
\hline d) Bicycles provided by employer or school & 19.9 & 80.1 & & 91 \\
\hline e) A safe place to leave a bike & 74.2 & 25.8 & & 87 \\
\hline f) Enough car parking spaces & 56.3 & 43.7 & & 93 \\
\hline g) Showers and changing rooms & 62.9 & 37.1 & & 93 \\
\hline h) Exercise classes & 39.1 & 60.9 & & 91 \\
\hline i) Sports club & 38.4 & 61.6 & & 89 \\
\hline j) Employer subsidised public transport & 48.3 & 51.7 & & 87 \\
\hline
\end{tabular}

\# without not applicable

ICC = Intraclass correlation coefficient

a weighted by the following formula $=$ item $1 \mathrm{a}+\left(12^{*}\right.$ item $\left.1 \mathrm{~b}\right)+\left(50^{*}\right.$ item $\left.1 \mathrm{c}\right)$; b: total sum score of all items; c: sum score of items $3 a$ \& $3 b$; : sum score of items $3 c \& 3 d$; e: sum score of reversed items $5 a, 5 e \& 5 f ;$ : sum score of reversed items $5 b, 5 c, 5 d$; 9 :sum score of items $6 b, 6 c$, reversed $6 d$; h:sum score of items $7 a, 7 c \& 7 d$ 


\section{Test-retest reliability}

Answer frequencies and mean scores for each item on the first assessment of the ALPHA questionnaire and their test-retest reliability scores are shown in Table 6. ICCs of the sum scores of each subscale ranged from 0.71 to 0.87 , with six of the nine ICCs above 0.75 , showing good testretest reliability. ICCs of the individual items ranged from 0.54-0.87, showing moderate to good stability. Proportions of agreement for all individual items ranged from $59-99 \%$.

In Table 7 the answer frequencies of each item on the first assessment of the ALPHA short were given, together with their test-retest reliability scores (ICC for the sum scores and proportions of agreement for the individual items). The ICC of the total sum score of the ALPHA short was 0.73 which indicates good test-retest stability. For the individual items the proportions of agreement were good, ranging from 85 to $95 \%$.

\section{Discussion}

The purpose of this study was to assess test-retest reliability, predictive validity and feasibility of the ALPHA environmental questionnaire in samples of men and women from several European countries.

\section{Reliability}

All but two of the subscales (distance to local facilities scale and the safety scale) in the ALPHA questionnaire showed low levels of internal consistency. This is appropriate for environmental variables as the aim of an environmental questionnaire is to sample possible indicators of one environmental construct which are often not intercorrelated, so Cronbach alphas are often low. In the literature similar internal consistency values for environmental scales are found e.g. the Cronbach alphas of the Cycling for Transport questionnaire range from 0.46 to 0.70 [25].

In the first testing, moderate to good test-retest reliability was evident for the ALPHA questionnaire (ICCs of the subscales ranged from 0.66-0.86); while in the second field testing all subscales showed good reliability (ICCs ranged from 0.71-0.87). The ICCs were not significantly different between two test-phases $(t=-1.207, p=0.247)$, but there was a significant increase $(t=-2.779, \mathrm{p}=0.008)$ in percentages of agreement from the first (range 52-99\%) to the second field testing (range 59-99\%). Similar testretest values have been reported for other environmental questionnaires, e.g. ICCs for the test-retest reliability of the NEWS subscales ranged from 0.58 to 0.80 in one study [12] and from 0.41-0.93 in another study [26]; for the IPAQ environmental module ICCs ranged from 0.36 to 0.98 [27]; and Evenson et al. reported ICC values from 0.64 to 0.91 for environmental items in their physical activity questionnaire [28].
Overall, our findings suggest that the final version of the ALPHA questionnaire has good reliability, comparable to that found in equivalent instruments.

The reliability results of the ALPHA short were more difficult to compare between both field tests, given the changes to answer categories (i.e. ICCs for the individual items could not be analysed). However, for the total score, reliability was good and of similar magnitude in both testing phases ( 0.75 and 0.73 respectively). For the individual items the proportion of agreement found in the first field testing $(50 \%$ to $83 \%)$ increased significantly $(t=-9.175, \mathrm{p}$ $<0.001$ ) in the second field testing ( $85 \%$ to $95 \%$ ); showing greater item stability in the later version. Reliability values of the ALPHA short compared favourably with other instruments, e.g. proportion of agreement for environmental items of South Carolina (47\% to 94\%), for the NEWS (33\% to 98\%) and for the St Louis Instrument (40\% to $96 \%)$ [26].

\section{Predictive validity}

In general, moderate predictive validity was found for both versions of the ALPHA environmental questionnaire. As expected, most associations were found between the environmental scales and "walking for transport" measured with the IPAQ. This is consistent with the transport literature in which urban planners show that certain environmental factors, like those included in the ALPHA questionnaire, are associated with increased levels of walking [29,30]. Also Saelens et al. [12] and De Bourdeaudhuij et al. [31] have found good associations between the attributes of built environment and walking for transport. It should be mentioned, however, that because of the cross-sectional nature of the current and previous studies $[8,32]$, no causal conclusions could be drawn. Therefore, the explanation that the built environment has a positive influence on physical activity levels could also be reversed i.e. people with higher physical activity levels perceive more physical activity opportunities in their built environment than people who are less physically active.

With the accelerometers, context-related physical activity could not be assessed, but almost all associations between the perceived environment and low physical activity were in line with the results of the IPAQ. Contrasting results between IPAQ and accelerometers were found for "safety from traffic" and "aesthetics". Somewhat unexpectedly, these environmental factors were related with lower levels of walking for transport measured with the IPAQ in women. However, we did find associations in the hypothesised direction with the Actigraph data, namely "safety from traffic" and "aesthetics" were related with respectively more minutes of vigorous physical activity and more minutes of physical activity at low intensity. In the literature, aesthetics and physical activity 
Table 7: Second field testing of the ALPHA short ( $=166)$ : Answer frequencies and test-retest reliability scores.

\begin{tabular}{|c|c|c|c|c|c|}
\hline \multirow[b]{2}{*}{ Item/Scale } & \multicolumn{3}{|c|}{ Answer frequencies } & \multicolumn{2}{|c|}{$\begin{array}{l}\text { Test-retest reliability } \\
\text { scores }\end{array}$} \\
\hline & Yes & No & NA & Agreement, \% & ICC \\
\hline Total & & & & & $0.73^{a}$ \\
\hline a) Most of the houses in my neighbourhood are detached houses & 33.7 & 66.3 & & 89 & \\
\hline b) There are many shops within easy walking distance of my home & 74.7 & 25.3 & & 92 & \\
\hline c) There is a bus/tram station within easy walking distance of my home & 92.2 & 7.8 & & 92 & \\
\hline d) There is a park within easy walking distance of my home & 84.9 & 15.1 & & 92 & \\
\hline e) Walking is dangerous because of the traffic in my neighbourhood & 7.8 & 92.2 & & 90 & \\
\hline $\begin{array}{l}\text { f) Walking is dangerous because of the level of crime in my } \\
\text { neighbourhood }\end{array}$ & 4.2 & 95.8 & & 95 & \\
\hline a) There are trees along the streets in my neighbourhood & 67.6 & 32.3 & & 85 & \\
\hline $\begin{array}{l}\text { g) At my home, I have small sports equipment such as a ball, racquets, ... } \\
\text { for my personal use }\end{array}$ & 82.5 & 17.5 & & 92 & \\
\hline $\begin{array}{l}\text { h) At my work or place of study I have bicycles provided by employer or } \\
\text { school }\end{array}$ & 10.8 & 77.1 & 12.0 & 93 & \\
\hline $\begin{array}{l}\text { i) At my work or place of study I have employer subsidized public } \\
\text { transport }\end{array}$ & 41.0 & 47.0 & 12.0 & 90 & \\
\hline
\end{tabular}

behaviour are consistently positively related, but the association between safety and physical activity behaviour is less consistent [8].

\section{Feasibility}

Both versions of the questionnaire appeared feasible in terms of completion time. The 49-item version was completed in a relatively short period of time compared to other environmental questionnaires requiring only an average of 6 minutes to complete. Given the low participant burden we recommend using this version as it gives a better overall picture of the built environment than ALPHA short.

\section{Strengths and Limitations}

The ALPHA questionnaire has undergone extensive conceptual and field testing and refinement. It is now ready for further assessment within different populations and environments across Europe.

One of the limitations in this study was the high education level of our participants in the second series of field testing compared with our first field test participants, which might explain some of the improvements seen in the test-retest scores.

A second limitation of this study are the different sampling methods (probability and non-probability) used in the three countries and the possible clustering within each country, which may have resulted in more positive results.
Another possible limitation is that objective environmental measurements were not included in the testing and thus the perceptions could not be compared with objective data. However, it has to take into account that objective and subjective measures of the build environment are two different concepts. Previous studies [33-35] found only a low to moderate agreement between objective and subjective measures. In some studies perceptions of the environment had a greater impact on PA behavior (or vice versa) compared to objective measured environment $[33,36]$ while another study found a greater influence of objective measures [37]. More research is needed to explore further the relationships and differences between perceived and objectively measured attributes of the environment.

Our questionnaire was based on extensive synthesis and adaptation of previous similar instruments [14] however this may repeat any systematic errors contained within these instruments $[14,38]$. We feel there remains a challenge in built environment and physical activity research of evaluating the congruence between definitions used in environmental questionnaires and adults' own definitions of neighbourhood.

\section{Conclusion}

The ALPHA questionnaire is a good instrument for measuring environmental perceptions related to physical activity behaviour, with moderate to good reliability, pre- 
dictive validity and feasibility. The instrument was developed in collaboration with an international expert group and was subject to different test phases. However, we acknowledge the considerable challenges of this field, and in light of the limitations outlined believe that further testing is required to improve generalisability to other European countries. Future testing will look to correlate the perceived environmental outcomes with other physical activity-related measures such as fitness, heart rate and geographic information system (GIS) measured objective environmental measures. By the means of this paper we would also like to make the ALPHA questionnaire available to other researchers who could further investigate whether our questionnaire represents an appropriate instrument for assessing perceptions of the environment related to physical activity across Europe. The questionnaire (in different languages) and a manual can be found on the IPEN website http://www.ipenproject.org.

\section{Additional material}

Additional file 1 International expert group. List of the members of the international expert group.

Additional file $\mathbf{2}$ ALPHA questionnaire. ALPHA measure of environmental perceptions: active travel and physical activity. For different languages and a manual see also http://www.ipenproject.org.

Additional file 3 ALPHA questionnaire (short form). ALPHA short measure of environmental perceptions: active travel and physical activity. Additional file $\mathbf{4}$ Adaptations. Adaptations of ALPHA and ALPHA short, made after the first field testing and second expert meeting

\section{Competing interests}

The authors declare that they have no competing interests.

\section{Authors' contributions}

$M S, P O, I D B, H R, C F, J M O$ and $H S$ identified the research question and design of this study as part of the ALPHA project. MV, JG, CG and ST collected the data. HS coordinated translation process and data collection, did the statistical analysis and drafted the manuscript. All authors contributed to synthesising the results and critical revision of the manuscript, and approved the final version.

\section{Acknowledgements}

This study is being carried out with financial support from the Commission of the European Communities, specifically the Public Health Programme 20032008 of the Directorate General Health and Consumer Protection Luxembourg, 800259 'Instruments for Assessing Levels of Physical Activity and related Health Determinants' (ALPHA). The study does not necessarily reflect the Commission's views and in no way anticipates the Commission's future policy in this area. The authors would like to thank Dirk Meusel, Benedicte Deforche, Greet Cardon and Femke De Meester for their help in the translation process and cognitive testing. We are extremely grateful to the international experts who were willing to participate in our expert meeting to discuss the results of our first field testing, and wish to give special thanks to all the participants for their willingness to participate.

\section{Author Details}

1 Department of Movement and Sports Sciences, Ghent University, Watersportlaan 2, 9000 Ghent, Belgium, ${ }^{2}$ Centre for Sport and Exercise Research, Staffordshire University, Leek Road, Stoke-on-Trent, Staffordshire ST4 2DF, UK, ${ }^{3}$ Nutritional Epidemiology Unit, UMR INSERM U557/INRA U1125/ CNAM/University Paris 13, CRNH IdF, 93017 Bobigny, France, ${ }^{4}$ Department of Nutrition, Pitie-Salpetriere Hospital (AP-HP), University Pierre et Marie CurieParis6, CRNH IdF, 75013 Paris, France, 5 Institute of Sports Science, University of Graz, Mozartgasse 14, 8010 Graz, Austria, ${ }^{6}$ Department of Public Health, University of Oxford, Old Road Campus, Headington, Oxford OX3 7LF, UK, 7 National Obesity Observatory, 4150 Chancellor Court, Oxford OX4 2GX, UK, 8 Urho Kaleva Kekkonen Institute for Health Promotion Research, FIN-33500 Tampere, Finland and ${ }^{9}$ Karolinska Institute, Department of Biosciences, Preventive Nutrition, Novum, 14157 Huddinge, Sweden

Received: 17 November 2009 Accepted: 26 May 2010 Published: 26 May 2010

\section{References}

1. Green LW, Richard L, Potvin L: Ecological foundations of health promotion. Am J Health Promot 1996, 10:270-281.

2. Sallis JF, Bauman A, Pratt M: Environmental and policy interventions to promote physical activity. Am J Prev Med 1998, 15:379-397.

3. Active Living Research. Introduction to the Active Living Research Reference List January - July 20082009

4. Active Living Research. Introduction to the Active Living Research Reference List Jul. - Dec. 20082009.

5. Wendel-Vos W, Droomers M, Kremers S, Brug J, Van Lenthe F: Potential environmental determinants of physical activity in adults: A systematic review. Obes Rev 2007, 8:425-440.

6. Ferreira I, van der HK, Wendel-Vos W, Kremers S, van Lenthe FJ, Brug J: Environmental correlates of physical activity in youth - a review and update. Obes Rev 2007, 8:129-154

7. Foster C, Hillsdon M, Jones A, Grundy C, Wilkinson P, White M, Sheehan B, Wareham N, Thorogood M: Objective Measures of the Environment and Physical Activity - Results of the Environment and Physical Activity Study in English adults. J Phys Activ Health 2009, 6:

8. Humpel N, Owen N, Leslie E: Environmental factors associated with adults' participation in physical activity: a review. Am J Prev Med 2002, 22:188-199.

9. Giles-Corti B, Donovan RJ: The relative influence of individual, social and physical environment determinants of physical activity. Soc Sci Med 2002, 54:1793-1812

10. Emery J, Crump C, Bors P: Reliability and validity of two instruments designed to assess the walking and bicycling suitability of sidewalks and roads. Am J Health Promot 2003, 18:38-46

11. Kirtland KA, Porter DE, Addy CL, Neet MJ, Williams JE, Sharpe PA, Neff $L$, Kimsey CD Jr, Ainsworth BE: Environmental measures of physical activity supports: perception versus reality. Am J Prev Med 2003, 24:323-331.

12. Saelens BE, Sallis JF, Black JB, Chen D: Neighborhood-based differences in physical activity: an environment scale evaluation. Am J Public Health 2003, 93:1552-1558

13. Meusel D, Ruiz JR, Ortega FB, Hägströmer M, Bergman P, Sjöström M: Assessing Levels of Physical Activity in the European Population - the ALPHA project. Selección 2007, 16:9-12.

14. Spittaels H, Foster C, Oppert JM, Rutter H, Oja P, Sjöström M, De Bourdeaudhuij I: Assessment of environmental correlates of physical activity: development of a European questionnaire. Int J Behav Nutr Phys Act 2009, 6:39.

15. European commission: Guidelines for the development and criteria for the adoption of health survey instruments Luxembourg; 2005.

16. Smith TW: Developing comparable questions in cross-national surveys. In Cross-cultural survey methods Edited by: Harkness JA, Van de Vijver FJR Molder PH. NJ: Wiley; 2003

17. Cochrane T, Davey RC, Gidlow C, Smith GR, Fairburn J, Armitage CJ, Stephansen H, Speight S: Small area and individual level predictors of physical activity in urban communities: a multi-level study in Stoke on Trent, England. Int J Environ Res Public Health 2009, 6:654-677. 
18. Rzewnicki R, Vanden Auweele Y, De Bourdeaudhuij I: Addressing overreporting on the International Physical Activity Questionnaire (IPAQ) telephone survey with a population sample. Public Health Nutr 2003, 6:299-305

19. Craig CL, Marshall AL, Sjostrom M, Bauman AE, Booth ML, Ainsworth BE, Pratt M, Ekelund U, Yngve A, Sallis JF, Oja P: International physical activity questionnaire: 12-country reliability and validity. Med Sci Sports Exerc 2003, 35:1381-1395.

20. Tyron WW, Williams R: Fully proportional actigraphy: a new instrument. Behav Res Meth Instrum Comput 1996, 28:392-403.

21. Freedson PS, Melanson E, Sirard J: Calibration of the Computer Science and Applications, Inc. accelerometer. Med Sci Sports Exerc 1998, 30:777-781.

22. Nunnally J, Bernstein I: Psychometric Theory. New York: McGraw-Hill; 1994.

23. Portney L, White M: Foundations of clinical research. Applications to practice. New Yersey: Pearson Education Inc; 2009.

24. Fleiss J: Statistical methods for rates and proportions. New York: Wiley; 1981.

25. Titze S, Stronegger WJ, Janschitz S, Oja P: Association of builtenvironment, social-environment and personal factors with bicycling as a mode of transportation among Austrian city dwellers. Prev Med 2008, 47:252-259.

26. Brownson RC, Chang JJ, Eyler AA, Ainsworth BE, Kirtland KA, Saelens BE, Sallis JF: Measuring the environment for friendliness toward physical activity: a comparison of the reliability of 3 questionnaires. Am J Public Health 2004, 94:473-483.

27. Alexander A, Bergman $P$, Hägströmer M, Sjöström M: IPAQ environmental module; reliability testing. J Public Health 2006, 14:76-80.

28. Evenson KR, Eyler AA, Wilcox S, Thompson JL, Burke JE: Test-retest reliability of a questionnaire on physical activity and its correlates among women from diverse racial and ethnic groups. Am J Prev Med 2003, 25:15-22.

29. Chen DD: The science of smart growth. Sci Am 2000, 283:84-91.

30. Handy SL, Boarnet MG, Ewing R, Killingsworth RE: How the built environment affects physical activity: views from urban planning. Am J Prev Med 2002, 23:64-73.

31. De Bourdeaudhuij I, Teixeira PJ, Cardon G, Deforche B: Environmental and psychosocial correlates of physical activity in Portuguese and Belgian adults. Public Health Nutr 2005, 8:886-895.

32. Owen N, Humpel N, Leslie E, Bauman A, Sallis JF: Understanding environmental influences on walking: Review and research agenda. Am J Prev Med 2004, 27:67-76.

33. Prins RG, Oenema A, van der HK, Brug J: Objective and perceived availability of physical activity opportunities: differences in associations with physical activity behavior among urban adolescents. Int J Behav Nutr Phys Act 2009, 6:70

34. Lackey KJ, Kaczynski AT: Correspondence of perceived vs. objective proximity to parks and their relationship to park-based physical activity. Int J Behav Nutr Phys Act 2009, 6:53.

35. McGinn AP, Evenson KR, Herring AH, Huston SL, Rodriguez DA: Exploring associations between physical activity and perceived and objective measures of the built environment. J Urban Health 2007, 84:162-184

36. Maddison R, Hoorn SV, Jiang Y, Mhurchu CN, Exeter D, Dorey E, Bullen C, Utter J, Schaaf D, Turley M: The environment and physical activity: The influence of psychosocial, perceived and built environmental factors. Int J Behav Nutr Phys Act 2009, 6:19.

37. Lin L, Moudon AV: Objective versus subjective measures of the built environment, which are most effective in capturing associations with walking? Health Place 2010, 16:339-348.

38. Moudon AV, Lee C, Cheadle AD, Garvin C, Johnson D, Schmid TL, Weathers RD, Lin L: Operational definitions of walkable neighborhood: theoretical and empirical insights. J Phys Act Health 2006, 3:S99-S117.

doi: 10.1186/1479-5868-7-48

Cite this article as: Spittaels et al., Measuring physical activity-related environmental factors: reliability and predictive validity of the European environmental questionnaire ALPHA International Journal of Behavioral Nutrition and Physical Activity 2010, 7:48

\section{Submit your next manuscript to BioMed Central} and take full advantage of:

- Convenient online submission

- Thorough peer review

- No space constraints or color figure charges

- Immediate publication on acceptance

- Inclusion in PubMed, CAS, Scopus and Google Scholar

- Research which is freely available for redistribution 